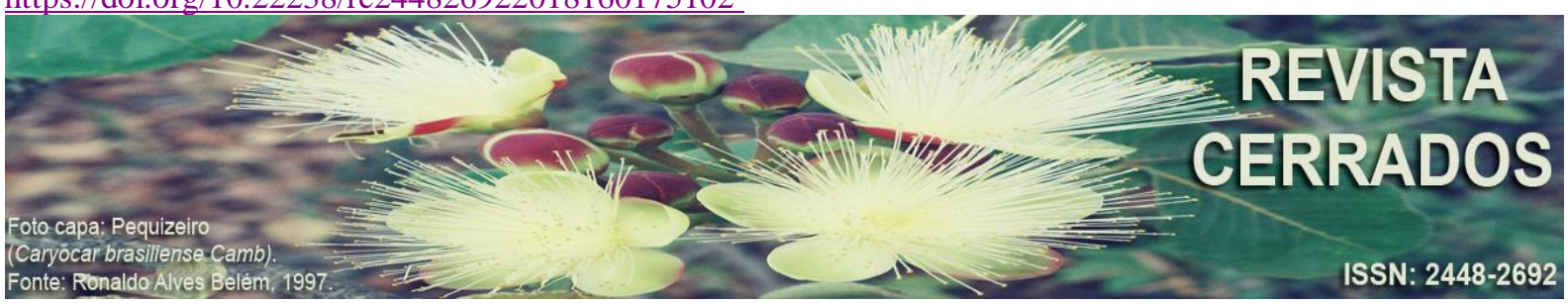

\title{
PROPOSTA DE RÓTULO AMBIENTAL COMO INDICADOR DE EFICIÊNCIA HÍDRICA PARA TORNEIRAS
}

\section{PROPOSAL OF ENVIRONMENTAL LABELLING AS INDICATOR OF THE HIDRIC EFICIENCY OF WATER TAPS}

\section{PROPUESTA DE ETIQUETAS AMBIENTALES COMO UN INDICADOR DE GRIFOS EFICIENTES DEL AGUA}

\author{
Antonio Carlos Demanboro \\ Pontifícia Universidade Católica de Campinas - PUC/Campinas \\ E-mail:< demanboro@puc-campinas.edu.br $>$. \\ Janaina do Prado Miñarro \\ Pontifícia Universidade Católica de Campinas - PUC/Campinas \\ E-mail: $<$ janaina_minarro@hotmail.com>.

\begin{abstract}
Regina Marcia Longo
Pontifícia Universidade Católica de Campinas - PUC/Campinas

E-mail:< rmlongo@uol.com.br>.

Sueli do Carmo Bettine

Pontifícia Universidade Católica de Campinas - PUC/Campinas

E-mail:< subettine@puc-campinas.edu.br $>$.
\end{abstract}

\begin{abstract}
RESUMO
Este trabalho tem como objetivo a proposição de rótulo ambiental de eficiência hídrica para torneiras. Parte-se da constatação que a água é um recurso finito e fundamental para a manutenção da vida e que as ações antrópicas inadequadas quanto à sua preservação e gerenciamento têm acarretado crises hídricas, principalmente nos grandes centros urbanos. Discute-se a eficiência hídrica de torneiras nacionais e propõe-se a adoção de selo a ser estampado em suas embalagens. A rotulagem das torneiras visa informar, de forma objetiva e clara à população, o volume de água despendido no uso, oferecendo ao consumidor subsídios para uma escolha consciente quanto ao equipamento a ser adquirido. Conclui-se que a adoção da rotulagem ambiental, através do selo hídrico proposto, pode ser um importante instrumento para se alcançar o uso racional da água.
\end{abstract}

Palavras- chave: Rotulagem ambiental. Torneiras. Conservação de água. 
DEMANBORO, A. C.; MIÑARO, J. P.; LONGO, R. M.; BETTINE, S. C.

Proposta de rótulo ambiental como indicador de eficiência hídrica para torneiras

\begin{abstract}
This work has the objective of proposing an environmental label of water efficiency for faucets. It is based on the observation that water is a finite and fundamental resource for the maintenance of life and that inadequate anthropic actions regarding its preservation and management have led to water crises, especially in large urban centers. The water efficiency of national taps is discussed and it is proposed to adopt a seal to be stamped on its packaging. The labeling of faucets aims to inform the population, in an objective and clear way, the volume of water consumed, giving the consumer subsidies for a conscious choice as to the equipment to be purchased. It is concluded that the adoption of environmental labeling, through the proposed water seal, can be an important instrument for the rational use of water.
\end{abstract}

Keywords: Environmental labeling. Tap. Water preservation.

\title{
RESUMEN
}

Este trabajo tiene como objetivo la proposición de etiqueta ambiental de eficiencia hídrica para grifos. Se parte de la constatación que el agua es un recurso finito y fundamental para el mantenimiento de la vida y que las acciones antrópicas inadecuadas en cuanto a su preservación y gestión han acarreado crisis hídricas, principalmente en los grandes centros urbanos. Se discute la eficiencia hídrica de grifos nacionales y se propone la adopción de sello a ser estampado en sus embalajes. El etiquetado de los grifos pretende informar, de forma objetiva y clara a la población, el volumen de agua gastado en el uso, ofreciendo al consumidor subsidios para una elección consciente en cuanto al equipo a ser adquirido. Se concluye que la adopción del etiquetado ambiental, a través del sello hídrico propuesto, puede ser un importante instrumento para alcanzar el uso racional del agua.

Palabras clave: Etiqueta ambiental. Grifos. Conservación del agua.

\section{INTRODUÇÃO}

Um rótulo ambiental é uma "afirmação que indica os aspectos ambientais de um produto ou serviço", conforme definiç̧ão da ABNT NBR ISO 14020:2002 - Rótulos e declarações ambientais - Princípios gerais. Segundo Moura (2013) um dos pressupostos em que se baseia a rotulagem ambiental é o fato de que um produto possa ser produzido de formas diversas, e cada forma apresenta um impacto diferente. Outras denominações também são aplicadas para se referir às informações ambientais contidas nos rótulos dos produtos, como: "selo verde ou ecológico, declaração ambiental, rótulo ecológico, ecorrótulo, ecosselo e etiqueta ecológica" (IPEA, 2011).

Conforme enfatizam Preussler et. al. (2006) a rotulagem ambiental objetiva, por meio da conscientização de consumidores, promover uma progressiva melhora da qualidade 
DEMANBORO, A. C.; MIÑARO, J. P.; LONGO, R. M.; BETTINE, S. C.

Proposta de rótulo ambiental como indicador de eficiência hídrica para torneiras

ambiental de produtos, processos e serviços. A ABNT NBR ISO 14020:2002, tem como objetivo dos rótulos e declarações ambientais estimular a demanda e fornecimento de produtos que provoquem menor impacto ambiental, valendo-se da comunicação, tendo como consequência uma melhoria ambiental contínua, inspirada pelo mercado.

A norma da International Organization for Standardization (ISO) 14020:2000 é mundialmente utilizada como base para estabelecer princípios orientadores visando o desenvolvimento e uso de rótulos e declarações ambientais, tendo outras normas de suas séries como complemento. Este trabalho tem como objetivo discutir a eficiência hídrica de torneiras nacionais, bem como propor sua rotulagem, por selo estampado em embalagens e torneiras.

\section{PANORAMA MUNDIAL DA ROTULAGEM DE EFICIÊNCIA HÍDRICA}

A Austrália desenvolveu seu sistema de rotulagem de eficiência hídrica denominado WELS (Water Efficiency Labelling and Standards), no ano de 2005 e em julho de 2006 tornou-se obrigatório em todo o país. Baseada em normas britânicas e estadunidenses e abrangidos pela norma da Austrália e Nova Zelândia AS/NZS 6400:2005 - Eficiência de água nos produtos - Classificação e rotulagem, o selo permite que o consumidor possa comparar a eficiência hídrica de produtos diferentes através do rótulo na embalagem (WELS, 2015).

Assim, todos os produtos disponíveis no mercado da Austrália passam por um cadastro e são etiquetados antes de serem vendidos. Os produtos irregulares recebem notificações e, em casos reincidentes ou mais graves, sofrem penalidades através de multas (WELS, 2015). A rotulagem é classificada por estrelas (de zero a seis), conforme Figura 1. Quanto maior o número de estrelas, menor o uso de água utilizada pelo produto (torneira) e consequentemente maior economia na tarifa.

A rotulagem possui uma classificação de zero a seis estrelas, na qual mais estrelas indicam menos uso de água que o produto vai utilizar e consequentemente maior economia na tarifa pelo uso da água, conforme figura 1 (WELS, 2015). 
DEMANBORO, A. C.; MIÑARO, J. P.; LONGO, R. M.; BETTINE, S. C.

Proposta de rótulo ambiental como indicador de eficiência hídrica para torneiras

Figura 1 - Rótulo de eficiência hídrica para torneira do sistema australiano WELS

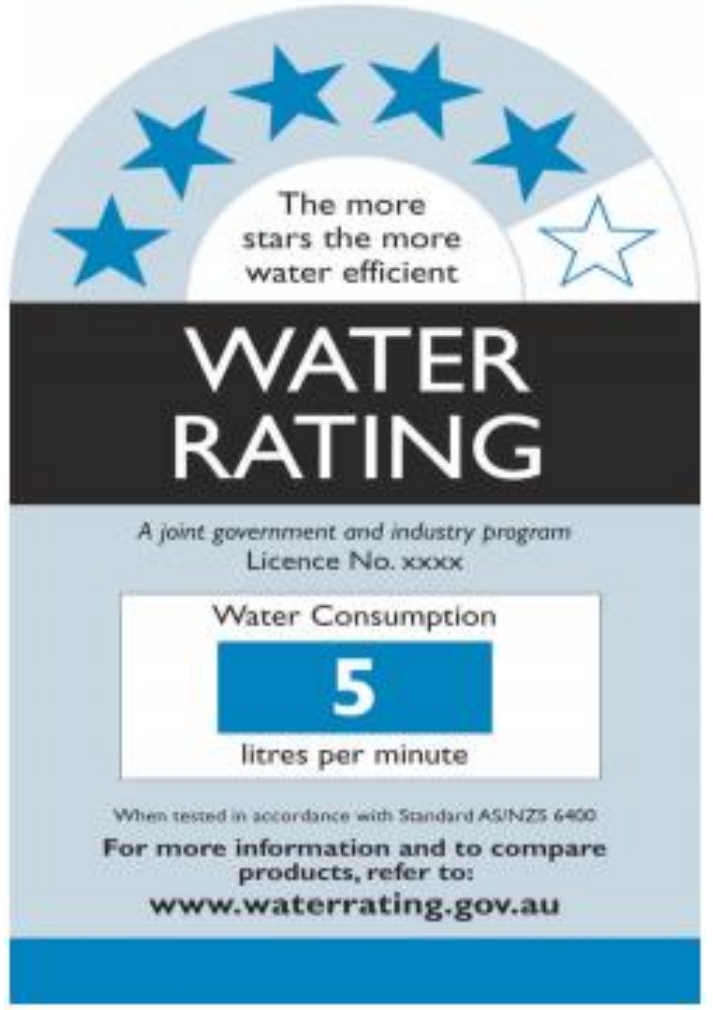

Fonte: WELS, 2015.

O sistema de classificação de estrelas para torneiras ocorre de acordo com faixas de vazão, conforme Tabela 1 .

Tabela 1. Classificação de estrelas do selo australiano WELS para torneiras

\begin{tabular}{c|c}
\hline $\begin{array}{c}\text { Classificação de } \\
\text { estrelas }\end{array}$ & Vazão (L/min) \\
\hline 0 & $>16$ \\
\hline 1 & 12 a 16 \\
\hline 2 & 9 a 12 \\
\hline 3 & 7,5 a 9 \\
\hline 4 & 6 a 7,5 \\
\hline 5 & 4,5 a 6 \\
\hline 6 & $<4,5$ \\
\hline
\end{tabular}

Fonte: KAPS; WOLF (2011) (adaptado).

Além das estrelas, o rótulo deve apresentar outras informações relevantes ao consumidor (WELS, 2015):

a) consumo de água em litros por uso para máquinas de lavar roupa, máquina de lavar louça e vaso sanitário; e consumo em litros para descarga total, metade e valor médio de bacia sanitária. b) vazão em litros por minuto para torneira e chuveiro.

Revista Cerrados, Montes Claros/MG, v.16, n. 1, p. 75-102, jan./jun.-2018. 
DEMANBORO, A. C.; MIÑARO, J. P.; LONGO, R. M.; BETTINE, S. C.

Proposta de rótulo ambiental como indicador de eficiência hídrica para torneiras

Na Europa, o WELL (Water Efficiency Labeling) é um sistema de classificação de produtos sanitários que tem como um dos objetivos o de atender a demanda populacional de informação e orientação na tomada de decisão de uma compra consciente (WELL, 2015). O rótulo WELL, conforme figura 2 e tabela 2, diferencia aplicações domésticas de públicas e comerciais, uma vez tais usos possuem diferentes perfis de requisitos (WELL, 2015). O requisito fundamental do WELL é a adequação às normas europeias existentes para o produto, e os laboratórios que realizam os testes devem ser credenciados de acordo com a ISO 17025 Requisitos gerais para a competência de laboratórios de ensaio e calibração.

Figura 2 - Rotulagem WELL de eficiência hídrica de torneiras de uso público - Europa

\section{WELL ruble}

Water Efficiency Label

\begin{tabular}{ll}
\hline Manufacturer: & Schell GmbH \& Co.KG \\
Product category: & Wash basin valve \\
Type: & Time/sensor valve \\
Model: & Celis E HD-K \\
Registration number: & WA10058-20110228
\end{tabular}

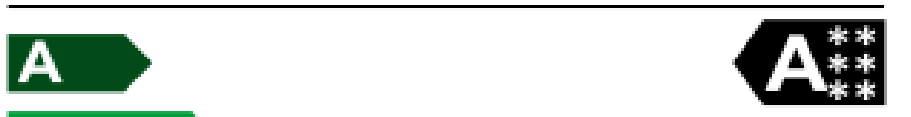

B

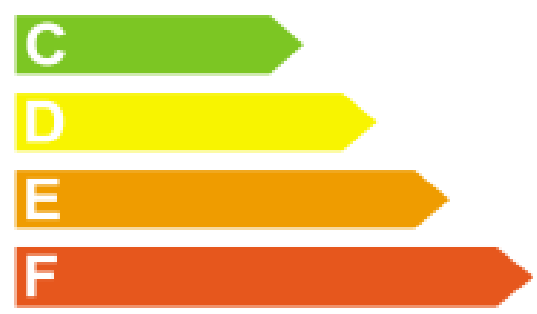

Water Efficiency Criteria

\begin{tabular}{lr}
\hline Flow rate $>6,0 \mathrm{l} / \mathrm{min} \leq 9,0 \mathrm{l} / \mathrm{min}$ & $\boldsymbol{*}$ \\
Controlled flow rate $\geq 4,0 \mathrm{lmin} \leq 6,0 \mathrm{l} / \mathrm{min}$ & $\boldsymbol{*}$ \\
\hline Flow-independent temperature setting & $\boldsymbol{*}$ \\
Temperature limit / Cold water valve & $\boldsymbol{*} \boldsymbol{*}$ \\
\hline Self-closing valve & $\boldsymbol{*}$ \\
Sensor valve & $\boldsymbol{*}$ \\
\hline
\end{tabular}

Information about use and installation: www.well-online.eu.

A Label of EUnited Valves

European Valve Manufacturers Association

Fonte: SCHELL (2015).

Revista Cerrados, Montes Claros/MG, v.16, n. 1, p. 75-102, jan./jun.-2018. 
DEMANBORO, A. C.; MiÑARO, J. P.; LONGO, R. M.; BETTINE, S. C.

Proposta de rótulo ambiental como indicador de eficiência hídrica para torneiras

A classificação de produtos de uso doméstico pode receber pontuação de até 4 estrelas, com classe de eficiência de "A" a "D”, já os de uso público podem receber pontuação de até 6 estrelas, com classe de eficiência de "A" a "F". Cada categoria (vazão, temperatura, tempo) pode receber no máximo 2 estrelas. A classificação possui validade de 5 anos, podendo ser estendida por mais 5 anos (WELL, 2015).

Tabela 2 - Classificação de eficiência hídrica de torneiras e respectivas vazões (L/min) WELL (Water Efficiency Labeling) - Europa

\begin{tabular}{|c|c|c|c|c|}
\hline & Uso & Classificação & Vazão (L/min) & Observações \\
\hline \multirow{2}{*}{ Doméstico } & \multirow{2}{*}{$\begin{array}{l}\text { Lavatório / bidê / } \\
\text { cozinha }\end{array}$} & 1 estrela & $>9$ a 12 & $\begin{array}{l}\text { Depende da } \\
\text { pressão }\end{array}$ \\
\hline & & 2 estrelas & 6 a 9 & $\begin{array}{l}\text { Independe da } \\
\text { pressão }\end{array}$ \\
\hline \multirow{2}{*}{ Público } & \multirow{2}{*}{ Lavatório } & 1 estrela & $>9$ a 12 & $\begin{array}{l}\text { Depende da } \\
\text { pressão }\end{array}$ \\
\hline & & 2 estrelas & 6 a 9 & $\begin{array}{c}\text { Independe da } \\
\text { pressão }\end{array}$ \\
\hline
\end{tabular}

Fonte: SCHELL (2015).

O Voluntary Water Efficiency Labelling Scheme (WELS) - Hong Kong é uma iniciativa de conservação da água, desse governo, iniciada em 2010. Os produtos participantes devem ser identificados com um selo, que indica o nível de consumo de água e eficiência para o consumidor. O selo possui duas versões, a completa e a simplificada conforme figura 3 , onde a versão completa é afixada na embalagem e a versão simplificada pode ser afixada diretamente no produto (WSD, 2015).

A classificação da eficiência varia de 1 a 4 com cores e número de gotas de água representando o grau de eficiência; o grau 1 é o mais eficiente e apresenta uma gota preenchida indicando menor consumo de água (WSD, 2014). Conforme tabela 3 é possível visualizar a relação de grau de eficiência e vazão para torneiras sem misturador, ou seja: apenas para água fria. 
DEMANBORO, A. C.; MIÑARO, J. P.; LONGO, R. M.; BETTINE, S. C.

Proposta de rótulo ambiental como indicador de eficiência hídrica para torneiras

Figura 3 - Rotulagem de eficiência hídrica (WELS) de Hong Kong.
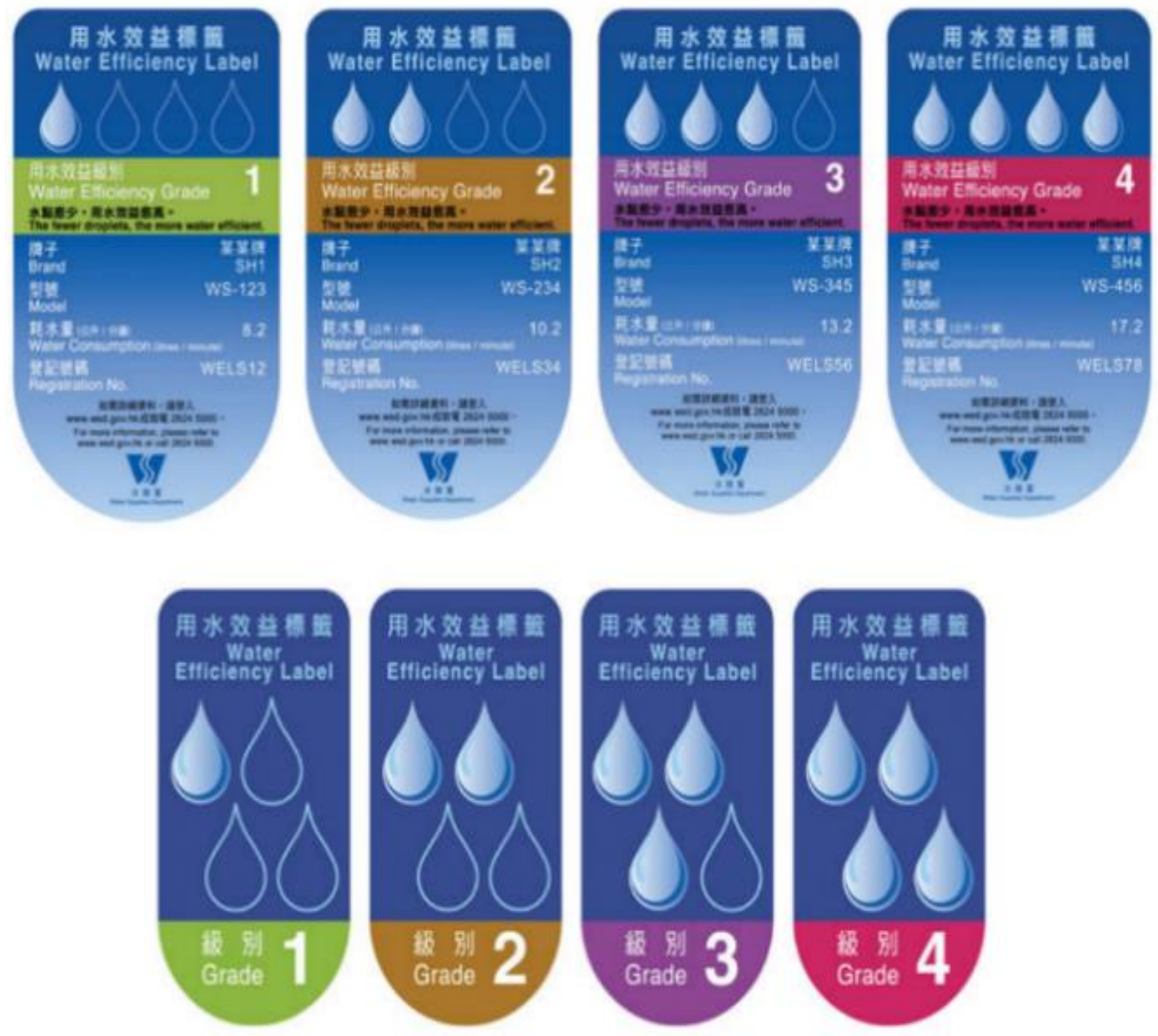

Fonte: WSD (2014).

O Sistema Water Efficiency Labelling Scheme (WELS) de Singapura, implantado em 2009, é uma iniciativa da Agência Nacional de Águas deste país. O objetivo do sistema é permitir que o consumidor auxilie na conservação dos recursos hídricos escassos do país (PUB, 2014). Possui quatro categorias de desempenho, sendo elas: zero, bom, muito bom e excelente, representadas pelo símbolo de visto $(\boldsymbol{V})$.

Conforme Tabela 4 é possível observar a classificação de eficiência hídrica para torneiras e suas respectivas vazões. 
DEMANBORO, A. C.; MIÑARO, J. P.; LONGO, R. M.; BETTINE, S. C.

Proposta de rótulo ambiental como indicador de eficiência hídrica para torneiras

Tabela 3 - Classificação de eficiência hídrica de torneiras sem misturador e respectivas vazões (L/min) - WELS (Voluntary Water Efficiency Labelling Scheme) - Hong Kong.

\begin{tabular}{c|c|c}
\hline $\begin{array}{c}\text { Grau de } \\
\text { eficiência }\end{array}$ & $\begin{array}{c}\text { Quantidade de } \\
\text { gotas }\end{array}$ & Vazão (L/min) \\
\hline 1 & 1 & $\leq 2$ \\
\hline 2 & 2 & $>2 \mathrm{a} 4$ \\
\hline 3 & 3 & $>4 \mathrm{a} 6$ \\
\hline 4 & 4 & $>6$ \\
\hline
\end{tabular}

Fonte: WSD (2015).

Tabela 4 - Classificação de eficiência hídrica de torneiras com misturador e respectivas vazões (L/min) - WELS (Water Efficiency Labelling Scheme) - Singapura.

\begin{tabular}{c|c|c|c|c}
\hline \multirow{2}{*}{ Equipamento } & Zero & Bom & Muito Bom & Excelente \\
\cline { 2 - 5 } & 0 & $\checkmark$ & $\checkmark \checkmark$ & $\checkmark \checkmark \checkmark$ \\
\hline $\begin{array}{c}\text { Torneira para } \\
\text { lavatório }\end{array}$ & $>6 \mathrm{~L} / \mathrm{min}$ & $>4 \mathrm{a} 6 \mathrm{~L} / \mathrm{min}$ & $>2 \mathrm{a} 4 \mathrm{~L} / \mathrm{min}$ & $\leq 2 \mathrm{~L} / \mathrm{min}$ \\
$\begin{array}{c}\text { Torneira para } \\
\text { cozinha }\end{array}$ & $>8 \mathrm{~L} / \mathrm{min}$ & $>6$ a $8 \mathrm{~L} / \mathrm{min}$ & $>4 \mathrm{a} 6 \mathrm{~L} / \mathrm{min}$ & $\leq 4 \mathrm{~L} / \mathrm{min}$ \\
\hline
\end{tabular}

Fonte: PUB (2014).

Na figura 4 (PUB, 2014), apresenta-se o rótulo utilizado para torneiras.

Figura 4. Rotulagem de eficiência hídrica (WELS) de Singapura para torneiras.

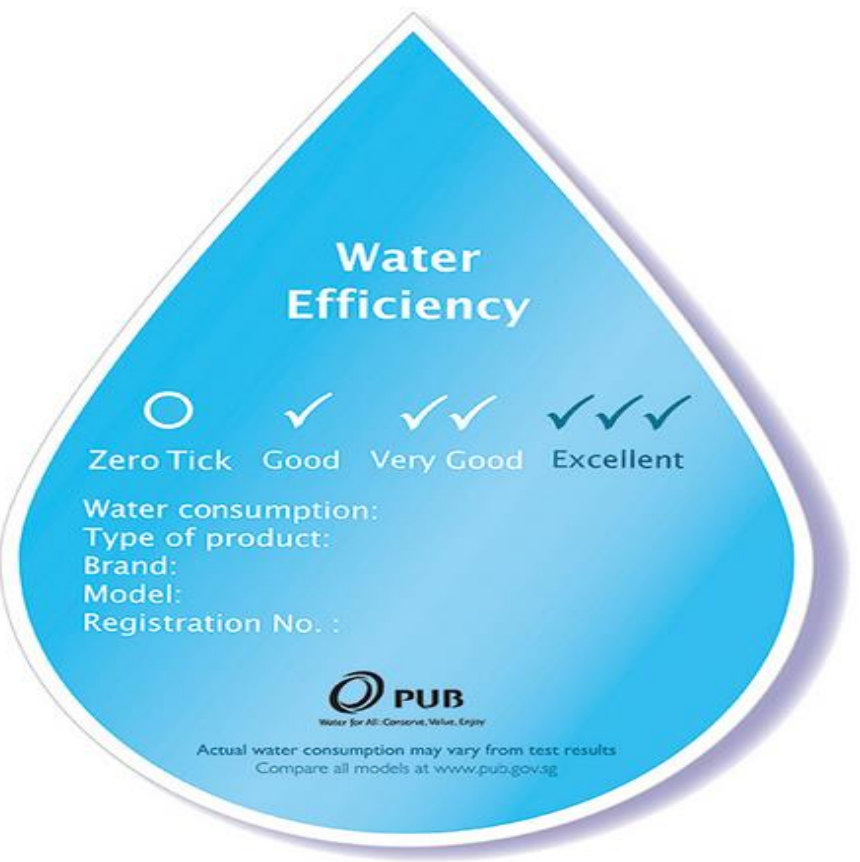

Fonte: PUB (2014).

Revista Cerrados, Montes Claros/MG, v.16, n. 1, p. 75-102, jan./jun.-2018. 
DEMANBORO, A. C.; MIÑARO, J. P.; LONGO, R. M.; BETTINE, S. C.

Proposta de rótulo ambiental como indicador de eficiência hídrica para torneiras

Os Estados Unidos conta com o WaterSense que é um programa de rotulagem de eficiência hídrica de equipamentos hidráulicos domésticos, em parceria com a "United States Environmental Protection Agency" - EPA. O objetivo deste programa é auxiliar os compradores, através do rótulo (Figura 15), na identificação de produtos que economizam água sem comprometer seu desempenho e qualidade (WATERSENSE, 2015).

A EPA exige que a certificação seja realizada por terceiros para garantir a confiança dos consumidores nos produtos (WATERSENSE, 2015). Para a obtenção do rótulo, o fabricante dos produtos que já foram analisados pelo programa assina um acordo de parceria com a WaterSense, tendo 12 meses para adequar seus produtos aos parâmetros especificados e obter o rótulo (WATERSENSE, 2015). Os parâmetros de vazão utilizados pelo WaterSense para torneiras de lavatório são de 5,68 litros por minuto a uma pressão de 413,68 kPa para vazão máxima e 3,03 litros por minuto com pressão de 137,89 kPa para vazão mínima, conforme tabela 5 (WATERSENSE, 2015).

Tabela 5 - Parâmetros de vazão para torneiras de lavatório - WaterSense

\begin{tabular}{c|c}
\hline \multicolumn{2}{c}{$\begin{array}{c}\text { Vazão para torneiras de } \\
\text { lavatórios }\end{array}$} \\
\hline Mínima & $3,03 \mathrm{~L} / \mathrm{min}$ \\
Máxima & $5,68 \mathrm{~L} / \mathrm{min}$ \\
\hline
\end{tabular}

Fonte: WATERSENSE (2015).

O rótulo WaterSense possui quatro apresentações (figura 5), sendo:

a) Etiqueta que identifica um produto eficiente em água que foi testado e certificado para cumprir os critérios EPA WaterSense para a eficiência e desempenho de forma independente;

b) Etiqueta promocional que anuncia a certificação de WaterSense nos produtos etiquetados e encoraja os consumidores a procurá-los;

c) Logo parceiro que apresenta o compromisso da organização para promover a eficiência de água, demonstrando um acordo de parceria assinado entre a organização e a EPA;

d) Logo promocional que promove o programa WaterSense em materiais que citam o programa de forma geral ou na educação do público sobre o mesmo (WATERSENSE, 2015).

Em setembro de 2011, o programa passou por revisão e, então, foi lançado o WaterSense 2.0 (WATERSENSE, 2015).

Revista Cerrados, Montes Claros/MG, v.16, n. 1, p. 75-102, jan./jun.-2018. 
DEMANBORO, A. C.; MIÑARO, J. P.; LONGO, R. M.; BETTINE, S. C.

Proposta de rótulo ambiental como indicador de eficiência hídrica para torneiras

Em Portugal existe a ANQIP (Associação Nacional para a Qualidade nas Instalações Prediais) que é uma associação técnico-científica cujo objetivo é promover a qualidade e eficiência das instalações prediais (ANQIP, 2015).

Figura 5 - Rotulagem WaterSense

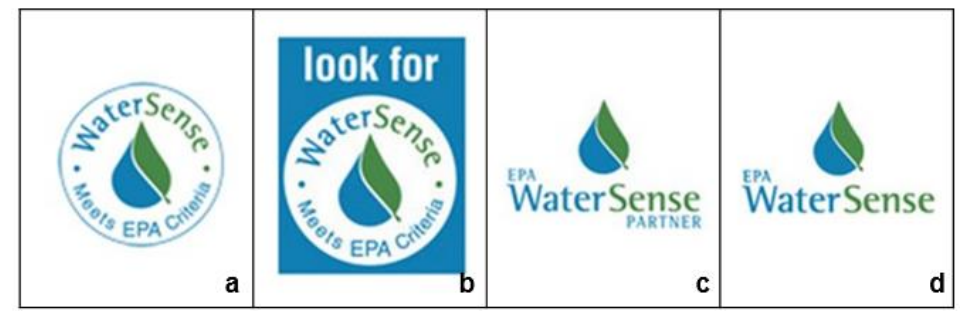

Fonte: WATERSENSE (2015).

O rótulo, conforme figura 6 , utiliza representação por letras de "A" a "E", com respectivas gotas que indicam o consumo de água, a letra $\mathrm{A}$ indica melhor eficiência e menor consumo de água, e a letra "E" indica menor eficiência hídrica, com maior consumo de água pelo equipamento. Também existem as categorias "A+" e "A++", que indicam equipamentos com maior eficiência. Os rótulos "A" e "A+" devem ter a indicação "Recomendável a utilização com arejador" (ANQIP, 2012).

Figura 6 - Rotulagem de eficiência hídrica da ANQIP

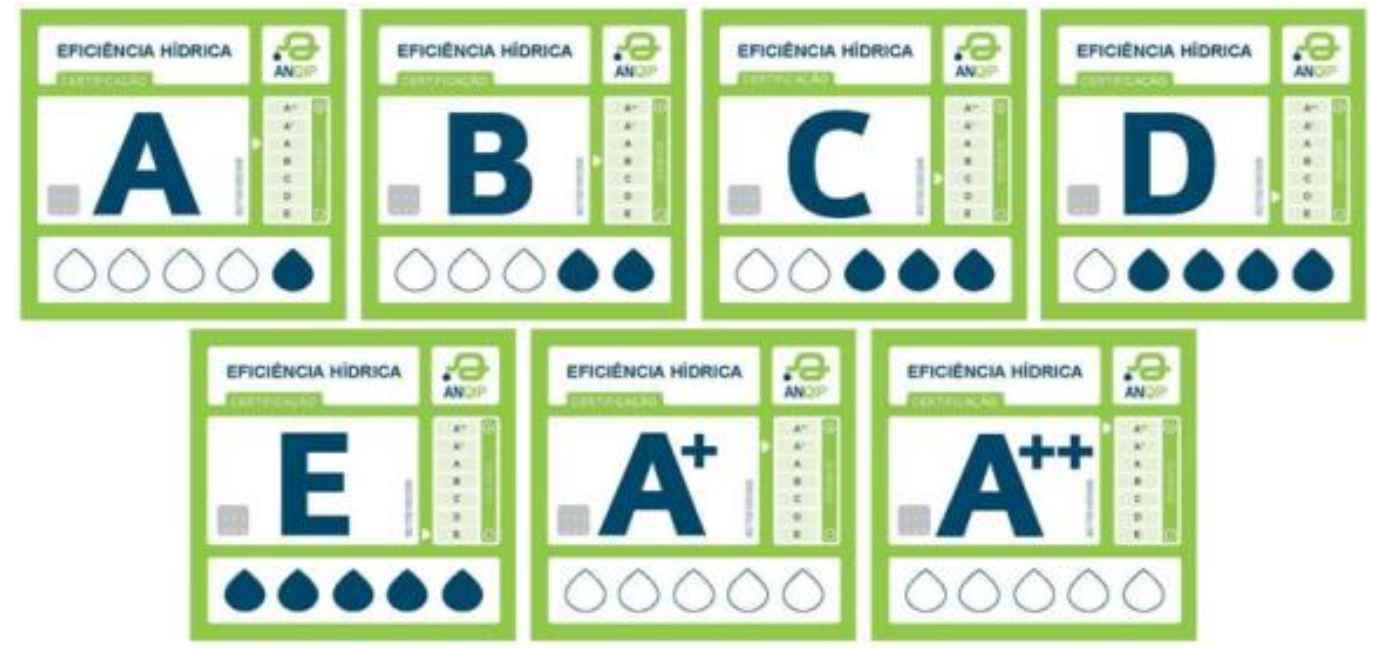

Fonte: ANQIP (2015).

A Especificação Técnica ANQIP $\mathrm{n}^{\circ} 0808$ trata das especificações para a atribuição de rótulos de eficiência hídrica ANQIP para torneiras e fluxômetros. Apresenta-se a classificação de torneiras de lavatório e torneiras de cozinha com respectivas faixas de vazão, 
DEMANBORO, A. C.; MiÑARO, J. P.; LONGO, R. M.; BETTINE, S. C.

Proposta de rótulo ambiental como indicador de eficiência hídrica para torneiras

conforme tabelas 6 e 7. Quanto a rotulagem ambiental no Brasil cabe observar que a versão brasileira da norma mundial de rótulos ambientais ISO 14020 foi publicada em 2002 pela Associação Brasileira de Normas Técnicas (ABNT).

Tabela 6 - Classificação de torneiras de lavatório - ANQIP.

\begin{tabular}{c|c|c|c}
\hline Vazão (L/min) & $\begin{array}{c}\text { Torneira de } \\
\text { lavatório }\end{array}$ & $\begin{array}{c}\text { Torneira de lavatório com } \\
\text { "eco-stop" ou arejador }\end{array}$ & $\begin{array}{c}\text { Torneira de lavatório com } \\
\text { "eco-stop" e arejador }\end{array}$ \\
\hline$\leq 2,0$ & $\mathrm{~A}+$ & $\mathrm{A}++(1)$ & $\mathrm{A}++(1)$ \\
\hline $2,0 \mathrm{a} \leq 4,0$ & $\mathrm{~A}+$ & $\mathrm{A}+$ & $\mathrm{A}++$ \\
$>4,0 \mathrm{a} \leq 6,0$ & $\mathrm{~B}$ & $\mathrm{~A}$ & $\mathrm{~A}+$ \\
\hline$>6,0 \mathrm{a} \leq 9,0$ & $\mathrm{C}$ & $\mathrm{B}$ & $\mathrm{A}$ \\
\hline$>9,0 \mathrm{a} \leq 12,0$ & $\mathrm{D}$ & $\mathrm{C}$ & $\mathrm{B}$ \\
\hline$>12,0$ & $\mathrm{E}$ & $\mathrm{D}$ & $\mathrm{C}$ \\
\hline
\end{tabular}

Nota: (1): Não se considera de interesse a utilização de temporizador nestes casos.

Fonte: ANQIP (2012).

Tabela 7 - Classificação de torneiras de cozinha - ANQIP.

\begin{tabular}{c|c|c|c}
\hline Vazão (L/min) & $\begin{array}{c}\text { Torneira de } \\
\text { cozinha }\end{array}$ & $\begin{array}{c}\text { Torneira de cozinha com } \\
\text { "eco-stop" ou arejador }\end{array}$ & $\begin{array}{c}\text { Torneira de cozinha com } \\
\text { "eco-stop" e arejador }\end{array}$ \\
\hline$\leq 4,0$ & $\mathrm{~A}+$ & $\mathrm{A}++(1)$ & $\mathrm{A}++(1)$ \\
\hline$>4,0 \mathrm{a} \leq 6,0$ & $\mathrm{~A}+$ & $\mathrm{A}+$ & $\mathrm{A}++$ \\
\hline$>6,0 \mathrm{a} \leq 9,0$ & $\mathrm{~B}$ & $\mathrm{~A}$ & $\mathrm{~A}+$ \\
\hline$>9,0 \mathrm{a} \leq 12,0$ & $\mathrm{C}$ & $\mathrm{B}$ & $\mathrm{A}$ \\
\hline$>12,0 \mathrm{a} \leq 15,0$ & $\mathrm{D}$ & $\mathrm{C}$ & $\mathrm{B}$ \\
\hline$>15,0$ & $\mathrm{E}$ & $\mathrm{D}$ & $\mathrm{C}$ \\
\hline
\end{tabular}

Nota: (1): Não se considera de interesse a utilização de temporizador nestes casos

Fonte: ANQIP (2012).

A ABNT desenvolveu em 1993 o rótulo ecológico denominado Marca ABNTQualidade Ambiental, conforme figura 7, oriundo de uma metodologia voluntária de desempenho ambiental de produtos e serviços, utilizado como forma de incentivo às empresas que pretendiam diferenciação no mercado que tal certificação pudessem proporcionar (ABNT, 2015).

Figura 7. Rótulo ambiental brasileiro ABNT-Qualidade Ambiental.

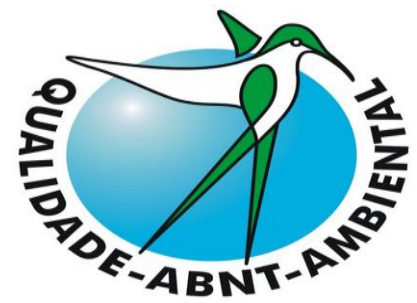

Fonte: ABNT (2012).

Revista Cerrados, Montes Claros/MG, v.16, n. 1, p. 75-102, jan./jun.-2018. 
DEMANBORO, A. C.; MIÑARO, J. P.; LONGO, R. M.; BETTINE, S. C.

Proposta de rótulo ambiental como indicador de eficiência hídrica para torneiras

Baseada na ABNT - NBR ISO 14024, a Marca ABNT - Qualidade Ambiental identifica os produtos com menor impacto sobre o meio ambiente, considerando todo o ciclo de vida do produto (ABNT, 2012).

\section{ROTULAGEM DE EFICIÊNCIA HÍDRICA NO BRASIL}

O Brasil não possui um Programa representativo de eficiência hídrica. Porém, de acordo com Silva (2012) em sua publicação no Senado Federal, o "rascunho zero" da Conferência das Nações Unidas sobre o Desenvolvimento Sustentável, a Rio+20, realizada em 2012, indica a necessidade de "implementação de gerenciamento integrado de recursos hídricos e planos de eficiência hídrica" no acordo número 69 do Relatório de Acordos da Conferência (RIO+20, 2012). O desenvolvimento de rotulagem ambiental para eficiência hídrica de aparelhos hidráulicos está atualmente em fase de discussão para futura criação do Programa Brasileiro de Rotulagem Ambiental (MMA, 2015).

O Instituto Nacional de Metrologia, Qualidade e Tecnologia (INMETRO) apresentou sua Agenda Regulatória ano 2015-2016, que tem como objetivo geral apresentar os temas em estudo. $\mathrm{O}$ item de etiquetagem de produtos que utilizam água faz parte desta agenda e tem como objetivo o estudo do programa WELS, desenvolvido na Austrália, para avaliar uma possível adaptação para o Brasil. Tal estudo tem como unidade responsável a Diretoria de Avaliação da Conformidade e apresenta o status de "Concluído" quando consultados os documentos disponíveis no site do INMETRO (INMETRO, 2015a). Em abril de 2015 o INMETRO implantou o Grupo de Trabalho de eficiência hídrica e energética, sinalizando o objetivo de desenvolver novos projetos de eficiência hídrica para o país (INMETRO, 2015b). Na sequência, foi apresentado em junho de 2015 ao Congresso Nacional pelo Deputado Marcos Abrão o Projeto de Lei (PL) n 2.049/2015, que institui o Selo PróÁgua, "para certificação de eletrodomésticos e aparelhos sanitários com uso eficiente de água." (BRASIL, 2015).

Esse projeto apresenta proposta similar atribuindo a concessão do selo aos órgãos federais que compõe o Sistema Nacional do Meio Ambiente (SISNAMA) e do Sistema Nacional de Metrologia, Normalização e Qualidade Industrial (SINMETRO). Tal projeto também define que os fabricantes e importadores dos equipamentos enquadrados na lei em questão, deverão obedecer aos níveis máximos de consumo de água previsto na legislação Revista Cerrados, Montes Claros/MG, v.16, n. 1, p. 75-102, jan./jun.-2018. 
DEMANBORO, A. C.; MIÑARO, J. P.; LONGO, R. M.; BETTINE, S. C.

Proposta de rótulo ambiental como indicador de eficiência hídrica para torneiras

específica de cada equipamento, e terão prazos para se adequarem, podendo ter seus equipamentos recolhidos caso não cumpram as especificações que serão previstas.

\section{NORMAS BRASILEIRAS PARA TORNEIRAS}

Em setembro de 2015 a Associação Brasileira de Normas Técnicas (ABNT) apresentou a norma brasileira aplicável NBR 10281:2015 (Torneiras - Requisitos e métodos de ensaio), substituindo as normas NBR 10281:2003 (Torneira de pressão - Requisitos e métodos de ensaio), e a NBR 15748:2009 (Torneiras com mecanismos de vedação não compressíveis - Requisitos e métodos de ensaio) (ABNT, 2015). Outra norma aplicável às torneiras é a NBR 13713:2009 (Instalações hidráulicas prediais - Aparelhos automáticos acionados mecanicamente e com ciclo de fechamento automático - Requisitos e métodos de ensaio). Estas normas apresentam, entre vários requisitos, os valores mínimos de vazão que a torneira deve atender. Conforme tabela 8, é possível verificar as vazões mínimas exigidas por cada norma, incluindo as normas canceladas, para título de comparação.

Tabela 8 - Relação de vazões mínimas para torneiras exigidas pela ABNT

\begin{tabular}{|c|c|c|c|c|}
\hline Norma & Status & Tipo de aparelho & $\begin{array}{l}\text { Vazão mínima } \\
\text { (L/min) }\end{array}$ & Observações \\
\hline \multirow{2}{*}{$\begin{array}{l}\text { ABNT NBR } \\
10281: 2015\end{array}$} & \multirow{2}{*}{ Em vigor } & $\begin{array}{l}\text { Torneira para pia de } \\
\text { cozinha e de lavatório }\end{array}$ & 2,4 & \multirow{2}{*}{-} \\
\hline & & Demais torneiras & 3,0 & \\
\hline $\begin{array}{l}\text { ABNT NBR } \\
13713: 2009\end{array}$ & Em vigor & \begin{tabular}{|c|} 
Aparelhos automáticos \\
acionados \\
mecanicamente e com \\
ciclo de fechamento \\
automático \\
\end{tabular} & 2,4 & $\begin{array}{l}\text { Pressão dinâmica } \\
\text { da água de } 15 \mathrm{kPa}\end{array}$ \\
\hline \multirow{2}{*}{$\begin{array}{l}\text { ABNT NBR } \\
10281: 2003\end{array}$} & \multirow{2}{*}{$\begin{array}{c}\text { Substituída } \\
\text { pela ABNT } \\
\text { NBR } \\
10281: 2015\end{array}$} & $\begin{array}{c}\text { Torneira de pressão } \\
\text { sem arejador }\end{array}$ & 6,0 & \multirow{2}{*}{$\begin{array}{l}\text { Pressão dinâmica } \\
\text { da água de } 15 \mathrm{kPa}\end{array}$} \\
\hline & & $\begin{array}{l}\text { Torneira de pressão } \\
\text { com arejador }\end{array}$ & 3,0 & \\
\hline \multirow{4}{*}{$\begin{array}{l}\text { ABNT NBR } \\
15748: 2009\end{array}$} & \multirow{4}{*}{$\begin{array}{l}\text { Cancelada e } \\
\text { substituída } \\
\text { pela ABNT } \\
\text { 10281:2015 }\end{array}$} & $\begin{array}{c}\text { Torneiras para pia de } \\
\text { cozinha e de lavatórios } \\
\text { com arejador }\end{array}$ & 2,4 & \multirow{4}{*}{$\begin{array}{c}\text { Pressão dinâmica } \\
\text { mínima da água de } \\
15 \mathrm{kPa}\end{array}$} \\
\hline & & $\begin{array}{c}\text { Torneiras para pia de } \\
\text { cozinha e de lavatórios } \\
\text { sem arejador }\end{array}$ & 4,2 & \\
\hline & & $\begin{array}{c}\text { Torneiras em geral com } \\
\text { arejador }\end{array}$ & 3,0 & \\
\hline & & $\begin{array}{c}\text { Torneiras em geral sem } \\
\text { arejador }\end{array}$ & 6,0 & \\
\hline
\end{tabular}

Fonte: ABNT (2015); PINI (2015).

Revista Cerrados, Montes Claros/MG, v.16, n. 1, p. 75-102, jan./jun.-2018. 
DEMANBORO, A. C.; MIÑARO, J. P.; LONGO, R. M.; BETTINE, S. C.

Proposta de rótulo ambiental como indicador de eficiência hídrica para torneiras

Observa-se que a NBR 10281:2015 apresentou redução de 60\% da vazão mínima em relação a edição anterior, a NBR 10281:2003, equiparando a vazão mínima para torneiras de pia de cozinha e de lavatórios com NBR 13713:2009. As normas brasileiras da ABNT não indicam o valor de vazão máxima para as torneiras, mas alguns países membros da União Europeia possuem regulamentos para a vazão máxima de torneiras, conforme tabela 9.

Tabela 9 - Vazões máxima para torneiras de países membros da União Européia.

\begin{tabular}{|c|c|c|c|}
\hline País & Programa & $\begin{array}{l}\text { Vazão máxima torneiras - } \\
\text { lavatórios (L/min) }\end{array}$ & $\begin{array}{c}\text { Vazäo máxima } \\
\text { torneiras - cozinha } \\
\text { (L/min) }\end{array}$ \\
\hline Áustria & $\begin{array}{c}\text { Ecolabel para eficiência de torneiras } \\
\text { sanitárias }\end{array}$ & $6 \mathrm{~L} / \mathrm{min}$ & $9 \mathrm{~L} / \mathrm{min}$ \\
\hline Portugal & $\begin{array}{l}\text { ANQIP - Associação Nacional para a } \\
\text { Qualidade nas Instalações Prediais }\end{array}$ & \multicolumn{2}{|c|}{ Classes $\mathrm{A}++\mathrm{a} \mathrm{E}$} \\
\hline Itália (Avigliana - Piemonte) & Normas de construção & $8-12 \mathrm{~L} / \mathrm{min}$ & 8-12 L/min \\
\hline Itália (Sassari - Sardenha) & Regulamento do município & $8 \mathrm{~L} / \mathrm{min}$ & - \\
\hline Letônia & $\begin{array}{c}\text { Certificado Verde para serviços de } \\
\text { alojamento turístico }\end{array}$ & $8 \mathrm{~L} / \mathrm{min}$ & $8 \mathrm{~L} / \mathrm{min}$ \\
\hline Luxemburgo & $\begin{array}{c}\text { Ecolabel para serviços de alojamento } \\
\text { turístico }\end{array}$ & $10 \mathrm{~L} / \mathrm{min}$ & $10 \mathrm{~L} / \mathrm{min}$ \\
\hline Holanda & Ecolabel para campings & $8,5 \mathrm{~L} / \mathrm{min}$ & $9 \mathrm{~L} / \mathrm{min}$ \\
\hline Países nórdicos & Rótulo ecológico para hotéis e hostels & $8 \mathrm{~L} / \mathrm{min}$ & $8 \mathrm{~L} / \mathrm{min}$ \\
\hline Eslováquia & $\begin{array}{c}\text { Ecolabel para serviçoes de } \\
\text { acomodações }\end{array}$ & $12 \mathrm{~L} / \mathrm{min}$ & $12 \mathrm{~L} / \mathrm{min}$ \\
\hline Espanha (Catalunha) & Ecolabel & \multicolumn{2}{|c|}{$8 \mathrm{~L} / \min$ (1-3 bar), $9 \mathrm{~L} / \mathrm{min}$ (3-5 bar) } \\
\hline
\end{tabular}

Fonte: Adaptado de KAPS; WOLF (2011).

Kaps e Wolf (2011) afirmam que a redução da vazão das torneiras pode provocar economias significativas de redução do consumo de água, assim como no consumo de energia, e consequentemente na redução de impactos ambientais relacionados a este consumo, e isso é possível sem necessariamente reduzir o desempenho do equipamento. Citam também que a determinação de vazões mínimas muito baixas, poderiam influenciar de forma negativa a qualidade dos produtos e assim diminuir a atratividade ao consumidor final. Por esta razão, Kaps e Wolf (2011) defendem que é necessário definir parâmetros que atendam a aceitação do consumidor para se atingir o sucesso de rótulos ecológicos no mercado. Considerar o uso 
DEMANBORO, A. C.; MIÑARO, J. P.; LONGO, R. M.; BETTINE, S. C.

Proposta de rótulo ambiental como indicador de eficiência hídrica para torneiras

das torneiras, seja para lavatório, cozinha, banheira ou áreas externas, é de essencial importância, uma vez que a necessidade de vazão disponível para cada uso é diferenciada. Os autores também afirmam que vazões mais baixas que $6 \mathrm{~L} / \mathrm{min}$ para torneiras podem causar desconforto para o usuário, e consequentemente não ser aceito no mercado.

\section{MATERIAIS E MÉTODOS}

A proposição da rotulagem para eficiência hídrica de torneiras seguiu os requisitos exigidos pelas normas ABNT NBR ISO 14020:2002, ABNT NBR ISO 14024:2004, ABNT NBR 10281:2015 e ABNT NBR 13713:2009. O selo PROCEL, amplamente conhecido, foi utilizado como parâmetro para a presente proposta de selo de eficiência hídrica. Foi realizada a verificação das normas aplicadas para torneiras disponíveis no mercado bem como a verificação da existência de indicação de vazão máxima e mínima das mesmas. Os dados e informações, utilizados na revisão bibliográfica, foram obtidos da rede mundial de computadores.

Paralelamente, foram levantados dados de vazão de torneiras em ambiente externo, com o objetivo de criar critérios de categorias de vazão para a rotulagem. As medições foram realizadas com a utilização de um cronômetro e dois recipientes plásticos que tiveram suas indicações de medidas de volume aferidas em laboratório através de uma proveta de vidro de 1 litro. Para a medição de volumes abaixo de $100 \mathrm{ml}$, foi utilizada uma proveta de vidro de $100 \mathrm{ml}$ para maior precisão do volume coletado. Cada torneira passou por um conjunto de cinco medições seguidas, com pausa de um minuto entre cada uma delas. As torneiras que continham fechamento automático tiveram seus tempos medidos no total do ciclo de funcionamento.

Para a elaboração da classificação de eficiência hídrica das torneiras foi considerada a adoção de 2,4 litros por minuto para a vazão mínima para pia de cozinha e lavatório, de forma a atender a legislação vigente pela ANBT NBR 10281:2015 e a ABNT NBR 13713:2009. No entanto, foi observado que existe a necessidade de vazões mínimas diferentes para usos diferentes, já que a utilização da torneira na cozinha pode requerer uma vazão maior para o conforto e atendimento das necessidades para a execução das atividades. Para definir parâmetros a serem utilizados, foram analisados os valores aplicados em outros países, porém a diferença de clima, cultura, costume, disponibilidade hídrica, entre outros Revista Cerrados, Montes Claros/MG, v.16, n. 1, p. 75-102, jan./jun.-2018. 
DEMANBORO, A. C.; MIÑARO, J. P.; LONGO, R. M.; BETTINE, S. C.

Proposta de rótulo ambiental como indicador de eficiência hídrica para torneiras

fatores, impedem que os valores sejam simplesmente utilizados, sem um estudo mais aprofundado para o cenário brasileiro.

Inicialmente foi realizada visita em 15 de julho de 2015 a um grande estabelecimento comercial que comercializa torneiras de diversas marcas, localizado no município de Campinas-SP. Obteve-se informações disponíveis relativas à vazão indicada nas embalagens, com a finalidade de encontrar os valores de vazões máximas das torneiras disponíveis no mercado.

Foram analisadas sete marcas: Deca, Docol, Lorenzetti, Meber, Celite, Fabrimar e Romar (figura 9). Todas as marcas apresentavam na embalagem referência à NBR 10281:2003 (Torneira de pressão - Requisitos e métodos de ensaio) ou à NBR 15748:2009 (Torneiras com mecanismos de vedação não compressíveis - Requisitos e métodos de ensaio) mas nenhuma delas indicava a vazão mínima ou máxima.

Figura 9 - Torneiras avaliadas.

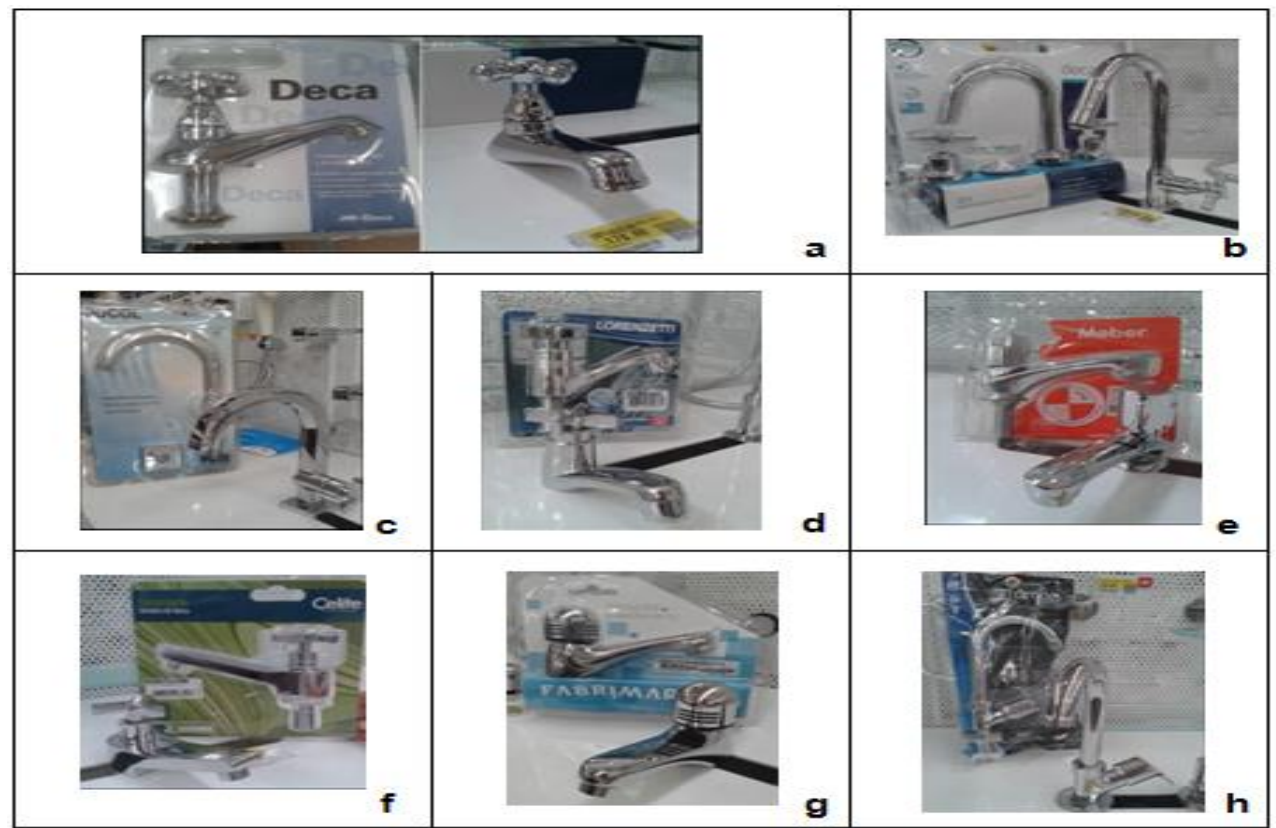

a) Deca. b) Deca. c) Docol. d) Lorenzetti. e) Meber. f) Celite. g) Fabrimar. h) Romar. Fonte: autores, 2016.

Portanto, foram realizados testes de vazão das torneiras a fim de verificar suas vazões máximas. Deve-se considerar que a pressão nominal a que as torneiras estão sujeitas tem grande influência em sua vazão, mas neste trabalho foi considerado apenas o valor da vazão, pressupondo que o método construtivo do local já deva ter seguido padrões de Norma com relação à pressão disponível, a fim de fornecer a vazão exigida pela legislação. 
DEMANBORO, A. C.; MiÑARO, J. P.; LONGO, R. M.; BETTINE, S. C.

Proposta de rótulo ambiental como indicador de eficiência hídrica para torneiras

Os testes de vazão foram realizados em oito torneiras instaladas em edificações em Campinas-SP e identificados dois tipos de arejadores nas torneiras avaliadas. Para diferenciá-los, foram utilizadas as seguintes denominações: arejador de contorno-(figura 10a), e arejador completo (figura 10b). As marcas e localizações das respectivas torneiras não serão apresentadas.

Figura 10 - Arejadores de vazão.

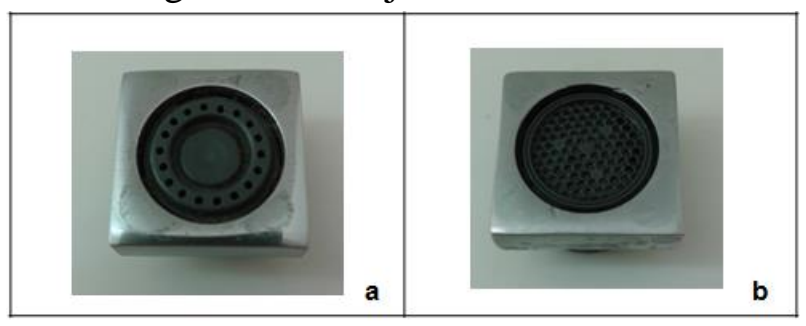

10. a) Arejador de contorno. 10.b) Arejador completo Fonte: autores, 2016.

As marcas e localizações das respectivas torneiras não serão apresentadas, pois não é objeto deste estudo avaliar o desempenho de diferentes marcas ou locais de instalação.

\section{RESULTADOS}

Dos testes aplicados foi possível verificar que as torneiras avaliadas apresentaram faixa de variação de vazão de 1,57 1/min a 15,37 1/min para aquelas com arejador completo, $1,02 \mathrm{l} / \mathrm{min}$ a $1,66 \mathrm{l} / \mathrm{min}$ para torneiras com arejador de contorno, e $5,15 \mathrm{l} / \mathrm{min}$ a $24,00 \mathrm{l} / \mathrm{min}$ para aquelas sem arejador.

$\mathrm{Na}$ Torneira 1 (acionamento por sensor e fechamento automático) foi avaliado o uso dos dois tipos de arejadores (de contorno e completo), assim como sem arejador e constatou-se que: a) o arejador completo reduziu em 6,74\% a vazão em relação à ausência de arejador, b) o arejador de contorno reduziu em 79,78\% a vazão em relação à ausência de arejador, c) o arejador de contorno reduziu em $79,31 \%$ a vazão em relação à vazão com arejador completo (gráfico 1). 
DEMANBORO, A. C.; MiÑARO, J. P.; LONGO, R. M.; BETTINE, S. C.

Proposta de rótulo ambiental como indicador de eficiência hídrica para torneiras

Gráfico 1 - Comparativo de vazões da Torneira 1.

\section{Torneira 1 - Acionamento por sensore fechamento automático - Vazão (L/min)}

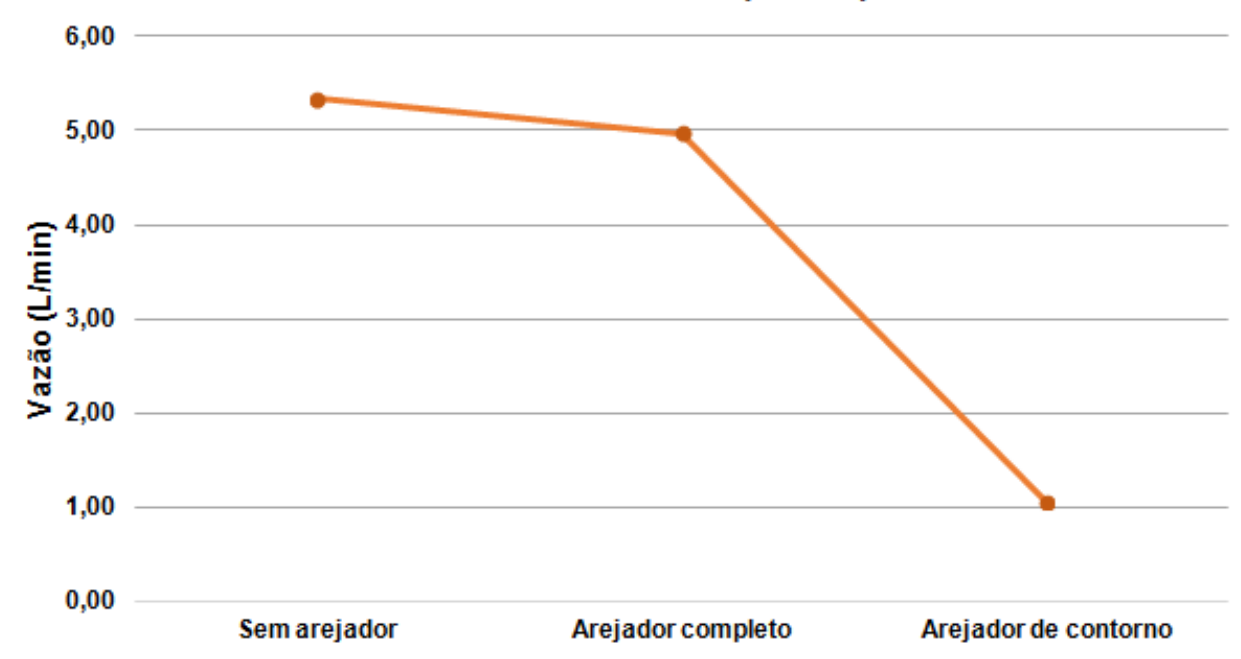

Fonte: autores, 2016.

Estas diferenças indicam que o tipo de arejador a ser instalado deve ser avaliado de acordo com a vazão disponível na torneira sem arejador, para que a legislação seja respeitada, assim como para o conforto do usuário.

$\mathrm{Na}$ avaliação da Torneira 2 (acionamento manual de rosa e fechamento manual), foram avaliadas duas situações, a vazão da torneira sem arejador e com arejador completo. Constatou-se que o arejador completo reduziu em 33,82\% a vazão em relação à ausência de arejador (gráfico 2).

Gráfico 2 - Comparativo de vazões da Torneira 3.

Torneira 3 - Acionamento manual (rosca) e fechamento manual - Vazão (L/min)

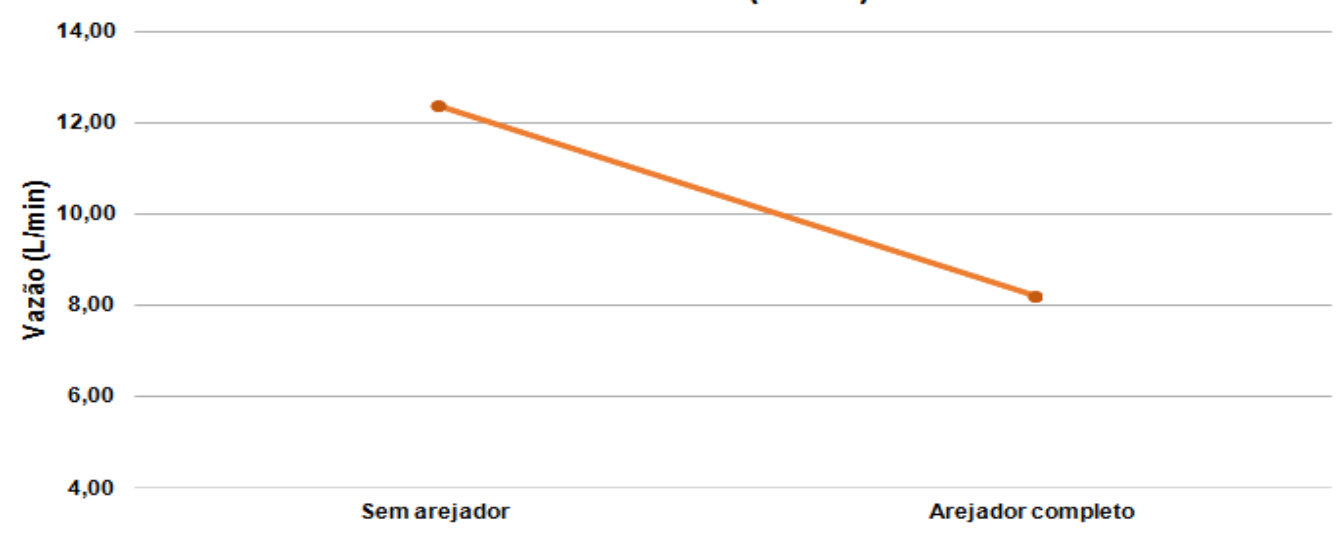

Fonte: autores, 2016.

Revista Cerrados, Montes Claros/MG, v.16, n. 1, p. 75-102, jan./jun.-2018. 
DEMANBORO, A. C.; MIÑARO, J. P.; LONGO, R. M.; BETTINE, S. C.

Proposta de rótulo ambiental como indicador de eficiência hídrica para torneiras

$\mathrm{Na}$ avaliação da Torneira 3 (acionamento manual por meio de alavanca e fechamento manual), foram avaliadas duas situações, a vazão da torneira sem arejador e com arejador completo. Constatou-se que o arejador completo reduziu em 40,88\% a vazão em relação à ausência de arejador (gráfico 3).

As torneiras 4 (de abertura manual com alavanca) e 5 (de abertura manual com 3 voltas e 1/2) apresentaram as maiores vazões, 14,32 1/min e $241 / \mathrm{min}$, respectivamente. Tais torneiras estão instaladas no primeiro andar de edifícios residenciais, com quinze andares (torneira 4) e sete andares (torneira 5). Não foi possível realizar as cinco medições pretendidas na torneira 5, devido à grande pressão disponível no ponto de instalação, que provocou um grande jato de água, inviabilizando as medições. Com base nas análises realizadas é possível observar que as vazões máximas encontradas são diversas, chegando a 24 1/min.

Registra-se que na revisão da NBR 10281:2015 não foi adotada vazão máxima permitida para uso, o que já é aplicado em outros países, tornando muito ampla a faixa de vazão que a torneira disponível no mercado deve atender; o que pode ocasionar desperdícios desnecessários, gerar desconforto físico ao usuário e desgaste na rede hidráulica devido à alta pressão. Dessa forma, a rotulagem aqui proposta não definirá a vazão máxima que a torneira possa atingir, mas sim um valor "acima de" na sua última categoria, como utilizado em diversos rótulos estrangeiros anteriormente apresentados neste trabalho.

Gráfico 3 - Comparativo de vazões da Torneira 4.

Torneira 4 - Acionamento manual (alavanca) e fechamento manual - Vazão (L/min)

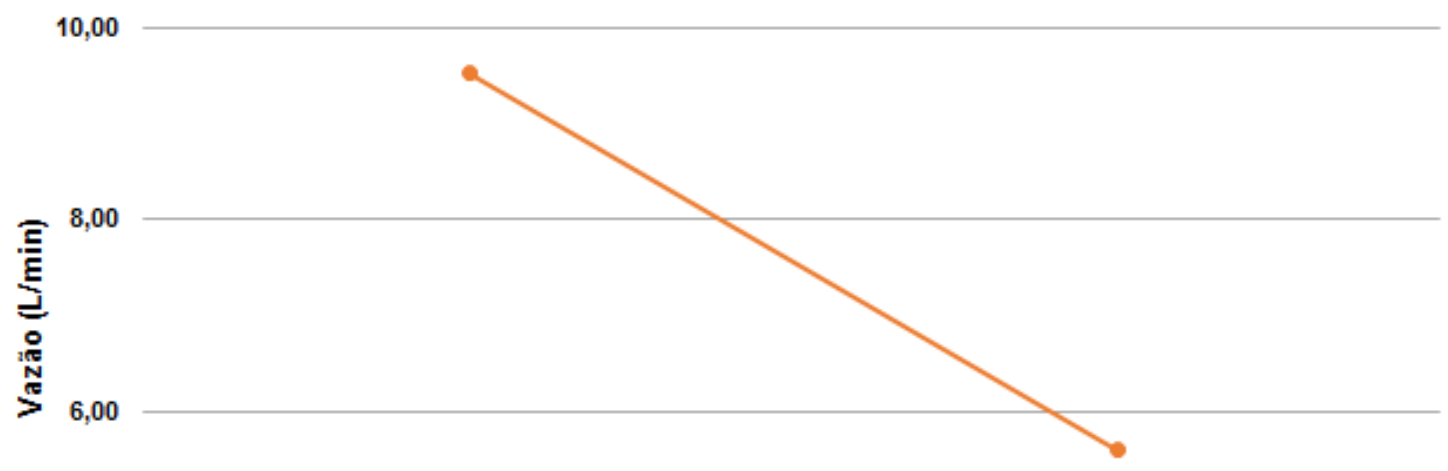


DEMANBORO, A. C.; MIÑARO, J. P.; LONGO, R. M.; BETTINE, S. C.

Proposta de rótulo ambiental como indicador de eficiência hídrica para torneiras

Foram realizadas, também, medições com três redutores de vazão com as seguintes dimensões de abertura: 2,5 mm, 4,0 mm e 5,5 mm, conforme figura 11 .

Figura 11. Redutores de vazão.

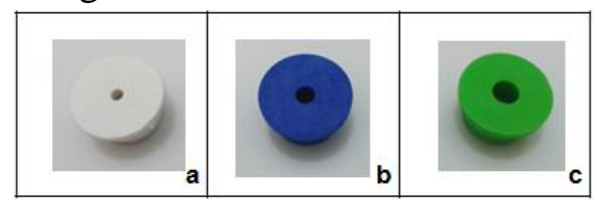

a) $2,5 \mathrm{~mm}$; b) $4,0 \mathrm{~mm}$; c) $5,5 \mathrm{~mm}$. Fonte: autores, 2016.

A diferença de vazão observada entre os redutores de menor abertura $(2,5 \mathrm{~mm}) \mathrm{e}$ de maior abertura $(5,5 \mathrm{~mm})$ foi de $55,96 \%$. Apresenta-se a resposta da vazão da torneira no uso dos diferentes redutores, conforme gráfico 4.

Com a análise comparativa de vazões para as diferentes aberturas dos redutores de vazão, observou-se que mesmo a menor abertura, de $2,5 \mathrm{~mm}$, apresentou vazão acima do mínimo estipulado pela norma aplicável, a ABNT NBR 10281, tanto em sua versão anterior, como na versão atualizada.

Gráfico 4 - Comparativo de vazão com utilização de redutores de vazão de aberturas diferentes.

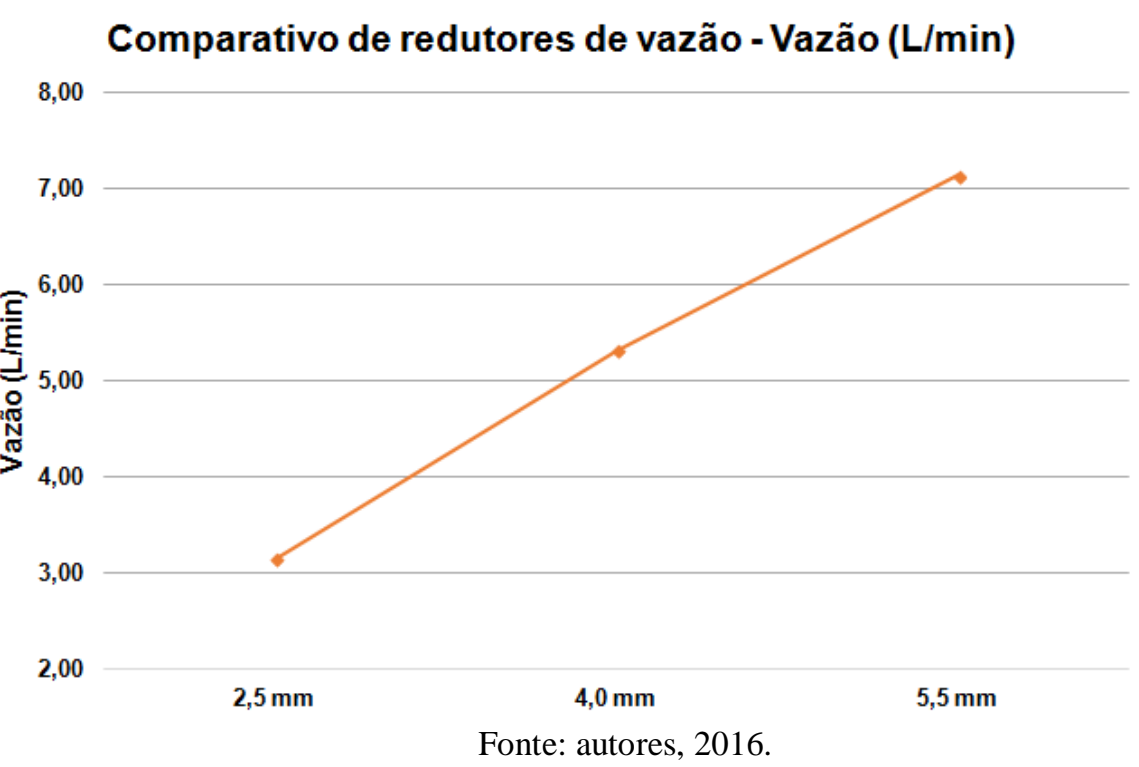

Observou-se, também, que a venda e o uso de arejadores e/ou restritores de vazão, sem a avaliação da pressão disponível e da vazão final após a instalação do dispositivo, tem como consequência torneiras com vazão insatisfatória. Essas não proporcionam conforto ao 
DEMANBORO, A. C.; MIÑARO, J. P.; LONGO, R. M.; BETTINE, S. C.

Proposta de rótulo ambiental como indicador de eficiência hídrica para torneiras

usuário, o que pode provocar efeito negativo para a população em relação ao uso de dispositivos economizadores de água. A presente proposta de rotulagem se enquadra na rotulagem ambiental de tipo I, conforme NBR ISO 14024:2004, sendo esta de caráter voluntário, onde as empresas interessadas devem requisitar a avaliação e posteriormente inserir a rotulagem nas embalagens das torneiras.

Nessa perspectiva, propõe-se como denominação "Programa de Conscientização de Conservação de Água", representado pela sigla PCCA, para o rótulo a ser inserido nos produtos certificados. Durante a elaboração deste trabalho, a NBR 10281:2003 foi substituída pela NBR 10281:2015. Além disso, a NBR 15748:2009 foi cancelada e também substituída pela Norma. As alterações nas NBRs indicaram a redução da vazão mínima para as torneiras, o que mostra que avanços estão sendo realizados no que se refere a regulamentação normativa brasileira, no entanto, em tais Normas não foi considerada a necessidade de vazões mínimas diferentes para torneiras utilizadas em lavatórios e em cozinhas, o que é considerado em normas regulamentadoras de outros países, uma vez que a vazão necessária para uso em lavatório é diferente daquela para uso em cozinha.

Na proposta de rotulagem aqui apresentada foi considerada a vazão mínima de 2,4 1/min para torneira de lavatório, conforme ABNT NBR 10281:2015 e vazão mínima de 5 1/min para torneira de cozinha, baseando-se nos dois rótulos ambientais citados neste trabalho: o selo WELS de Singapura e o selo ANQIP de Portugal, que apresentam 4 1/min e, então, foi acrescentado 1 1/min como margem de segurança devido às variáveis apresentadas ao longo deste trabalho.

Foram também definidas cinco categorias para o rótulo ambiental, apresentadas com letras (A, B, C, D e E) e símbolos de gotas que representam o uso da água. O uso da gota como símbolo é aplicável conforme ABNT NBR ISO 14021:2013, pois possui "vínculo direto e verificável entre o símbolo e o benefício alegado", no caso de economia de água.

A letra "A" indica o equipamento com maior eficiência hídrica e menor consumo de água, sendo representada por apenas uma gota de tom azul escuro e as outras quatro gotas em tom claro, como se estivessem "vazias", e assim sucessivamente, até a letra "E", que indica um equipamento com maior consumo de água, com as cinco gotas em tom de azul. São apresentadas as categorias e as respectivas faixas de vazões adotadas, conforme tabela 10. 
DEMANBORO, A. C.; MIÑARO, J. P.; LONGO, R. M.; BETTINE, S. C.

Proposta de rótulo ambiental como indicador de eficiência hídrica para torneiras

Tabela 10 - Categoria de vazões da rotulagem ambiental proposta.

\begin{tabular}{|c|c|c|c|}
\hline \multirow{2}{*}{ Letra } & \multirow{2}{*}{$\begin{array}{c}\text { Quantidade de } \\
\text { gotas }\end{array}$} & \multicolumn{2}{|c|}{ Vazão (L/min) } \\
\hline & & Lavatório & Cozinha \\
\hline$A$ & 1 & $\leq 3$ & $\leq 5$ \\
\hline$B$ & 2 & $>3 a \leq 6$ & $>5 a \leq 8$ \\
\hline C & 3 & $>6 a \leq 9$ & $>8 a \leq 11$ \\
\hline $\mathrm{D}$ & 4 & $>9 a \leq 12$ & $>11 a \leq 14$ \\
\hline$E$ & 5 & $>12$ & $>14$ \\
\hline
\end{tabular}

Fonte: autores, 2016.

O layout foi definido conforme figura 12, e deverá ser inserido na embalagem do produto. Também é proposta a aplicação de um adesivo em plástico para ser inserido no corpo da torneira (figuras 13 e 14), de modo que o consumidor reconheça que a torneira utilizada pelo estabelecimento é certificada pela rotulagem ambiental, assim como para identificar sua classe.

Figura 12 - Layout do rótulo ambiental PCCA proposto para torneiras com todas as categorias de eficiência hídrica.

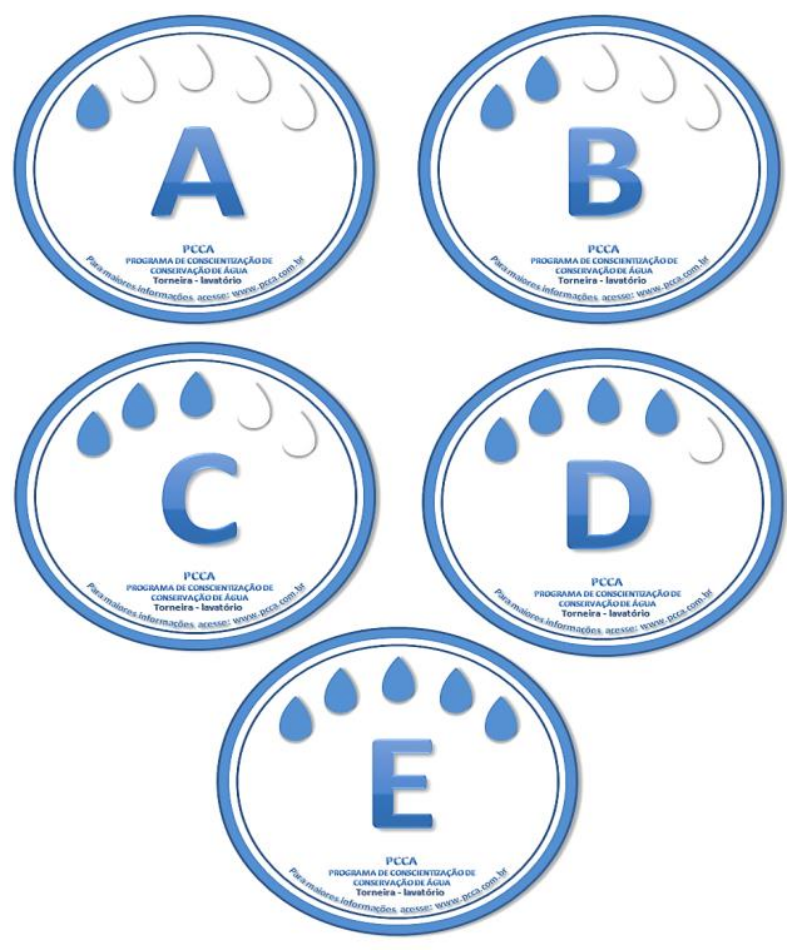

Fonte: autores, 2016.

Revista Cerrados, Montes Claros/MG, v.16, n. 1, p. 75-102, jan./jun.-2018. 
DEMANBORO, A. C.; MIÑARO, J. P.; LONGO, R. M.; BETTINE, S. C.

Proposta de rótulo ambiental como indicador de eficiência hídrica para torneiras

Figura 13 - Layout de adesivo PCCA a ser inserido no corpo da torneira.

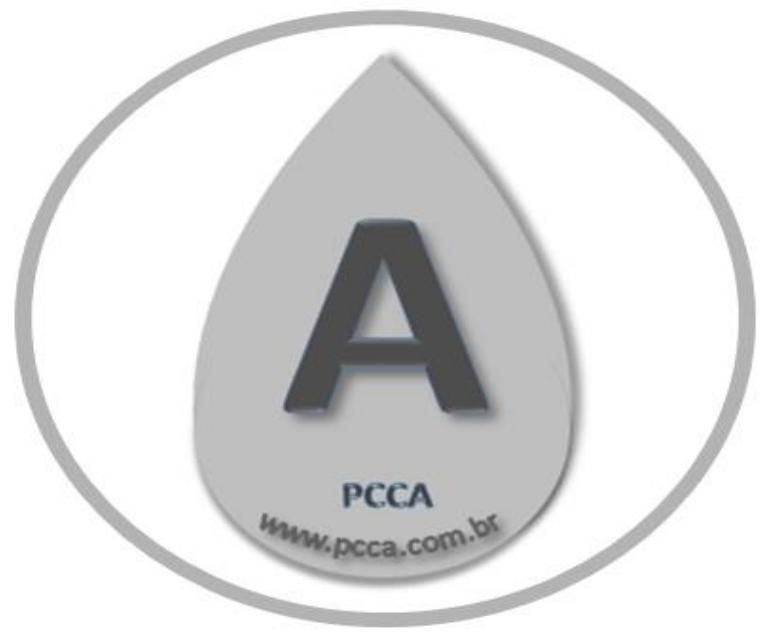

Fonte: autores, 2016.

A proposta inclui, ainda, um cartaz informativo a ser inserido nos estabelecimentos que comercializam as torneiras a fim de informar o consumidor sobre a nova rotulagem e seu funcionamento, bem como a importância da conservação da água.

Figura 14 - Torneira com o adesivo do PCCA aplicado

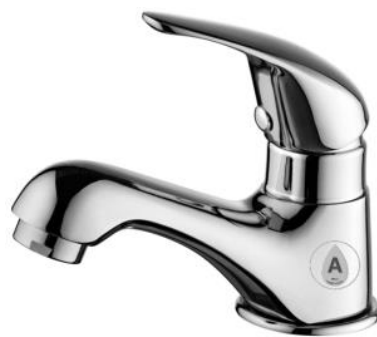

Fonte: Adaptado de ACESSIBILIDADE (2012).

A aplicação de uma nova rotulagem deve ser acompanhada de instrução e informação aos compradores, não só sobre sua metodologia, mas também em relação à conscientização da conservação da água, para que este comportamento seja inserido na cultura da população.

\section{CONCLUSÃO}

A problemática atual em relação à disponibilidade de recursos hídricos deve conduzir o setor produtivo e a sociedade na busca de melhores alternativas para uso racional 
da água. Uma maneira de promover tal prática é a informação clara para a população quanto as suas decisões relativas à implantação de equipamentos domésticos utilizadores de água.

No levantamento teórico desenvolvido no inicio deste trabalho foi possível observar que diversos países possuem programas de certificação de eficiência hídrica, e que no Brasil tais programas são incipientes ou carecem de detalhamento técnico/normativo. Neste sentido, foi proposta a adoção do selo de eficiência hídrica para torneiras, em todo o país.

Desenvolveu-se uma escala de eficiência hídrica (A a E) e os respectivos selos de eficiência hídrica, que serão importantes ferramentas para se atingir o aumento na eficiência no uso da água, tão importante face aos elevados custos de captação, tratamento e distribuição envolvidos; bem como para fazer frente às crises hídricas recorrentes, como a que aconteceu em 2014 na região Sudeste do Brasil.

Assim, este trabalho, baseando-se em uma ferramenta consagrada em vários países, propõe informar e orientar a população sobre o consumo de água dos equipamentos hidráulicos domésticos aplicando a rotulagem ambiental em torneiras, na qual se descrevem os volumes despendidos no seu uso.

\section{REFERÊNCIAS}

ABNT - Associação Brasileira de Normas Técnicas. Rótulo ecológico Marca ABNTQualidade Ambiental, 2015. Disponível em:

< http://www.abnt.org.br/rotulo/pt/>. Acesso em: 13 set. 2015.

ABNT - ASSOCIAÇÃO BRASILEIRA DE NORMAS TÉCNICAS. NBR ISO 14020:2002 Rótulos e declarações ambientais - Princípios gerais. Rio de Janeiro, 2002.

ABNT - Associação Brasileira de Normas Técnicas. Notícias: Torneiras - Requisitos e Métodos de Ensaio, 2015. Disponível em: http://www.abnt.org.br/noticias/4393torneiras-requisitos-e-metodos-de-ensaio>. Acesso em: 15 set. 2015.

ABNT - ASSOCIAÇÃO BRASILEIRA DE NORMAS TÉCNICAS. NBR 10281:2015 Torneiras - Requisitos e métodos de ensaio. Rio de Janeiro, 2015.

ABNT - ASSOCIAÇÃO BRASILEIRA DE NORMAS TÉCNICAS. NBR 15748:2009 Torneiras com mecanismos de vedação não compressíveis - Requisitos e métodos de ensaio. Rio de Janeiro, 2009. 
DEMANBORO, A. C.; MIÑARO, J. P.; LONGO, R. M.; BETTINE, S. C.

Proposta de rótulo ambiental como indicador de eficiência hídrica para torneiras

ABNT - ASSOCIAÇÃO BRASILEIRA DE NORMAS TÉCNICAS. NBR 13713:2009 Instalações hidráulicas prediais - Aparelhos automáticos acionados mecanicamente e com ciclo de fechamento automático - Requisitos e métodos de ensaio. Rio de Janeiro, 2009.

ANQIP - Associação Nacional para a Qualidade nas Instalações Prediais. Especificação Técnica 0808 - Especificações para a atribuição de rótulos de eficiência hídrica ANQIP a torneiras e fluxômetros. Portugal, 2012. Disponível em:

<http://repositorio.ipl.pt/bitstream/10400.21/2166/6/ETA_0808.2.pdf>. Acesso em: 27 set. 2015.

ANQIP - Associação Nacional para a Qualidade nas Instalações Prediais. Home, Quem somos, Especificações Técnicas. Portugal, 2015. Disponível em: <

http://www.anqip.com/index.php/pt/home>. Acesso em: 27 set. 2015.

BRASIL. Projeto de Lei no 2.049/2015. Institui o Selo Pró-Água, para certificação de eletrodomésticos e aparelhos sanitários com uso eficiente de água, Brasília, DF, jun. 2015b. Disponível em:

<http://www.camara.gov.br/proposicoesWeb/prop_mostrarintegra?codteor=1352101\&filena me=PL+2049/2015>. Acesso em: 16 ago. 2015.

ECOSTART - Produtos Sustentáveis. Ventilador de teto Universe Turbo com Luminária Cor Prata, 2015. Disponível em: <http://ecostart.com.br/produtos/index/ventilador-universeturbo-prata-com-luminaria-led>. Acesso em: 07 jul. 2015.

INMETRO - Instituto Nacional de Metrologia, Qualidade e Tecnologia. Agenda Regulatória do INMETRO 2015-2016, Categoria: Estudo. 2015a. Disponível em:

<http://www.inmetro.gov.br/qualidade/pdf/agenda-regulatoria.pdf>. Acesso em: 17 set. 2015.

INMETRO - Instituto Nacional de Metrologia, Qualidade e Tecnologia. Inmetro implanta Grupo de Trabalho de eficiência hídrica e energética. Rio de Janeiro, 2015b. Disponível em: <http://www.inmetro.gov.br/imprensa/releases/inmetro_implanta_grupo_de_trabalho_de_efic iencia_hidrica_e_energetica.pdf $>$. Acesso em: 26 set. 2015.

IPEA - Instituto de Pesquisa Econômica Aplicada. Comunicados do IPEA. Série no 82: Eixos do Desenvolvimento Brasileiro. Sustentabilidade Ambiental no Brasil: biodiversidade, economia e bem-estar humano. O uso do Poder de Compra para a Melhoria do Meio Ambiente. Brasília, 2011. Disponível em:

$<$ http://cpsustentaveis.planejamento.gov.br/assets/conteudo/uploads/rotulagemambientalipea. pdf $>$. Acesso em: 10 set. 2015.

ISO - International Organization for Standardization. ISO 14020:2000. Abstract. Genebra Suíça, 2015. Disponível em:

<http://www.iso.org/iso/home/store/catalogue_tc/catalogue_detail.htm?csnumber=34425>. Acesso em: 13 set. 2015.

KAPS, R.; WOLF, O. Development of European Ecolabel and green public procurement criteria for sanitary tapware - Taps and Showerheads. Institute for Prospective 
DEMANBORO, A. C.; MIÑARO, J. P.; LONGO, R. M.; BETTINE, S. C.

Proposta de rótulo ambiental como indicador de eficiência hídrica para torneiras

Technological Studies Sustainable Production and Consumption Unit. Seville, Espanha, 2011. Disponível em:

<http://susproc.jrc.ec.europa.eu/ecotapware/docs/1st\%20draft_Technical_background_report_ Criteria_for_taps_and_showerheads_revised.pdf>. Acesso em: 24 set. 2015.

MMA - Ministério do Meio Ambiente. Ecomercados e Negócios Sustentáveis. 2015.

Disponível em: <http://www.mma.gov.br/governanca-ambiental/economia-

verde/ecomercados-e-neg\%C3\%B3cios-sustent\%C3\%A1 veis>. Acesso em: 09 set. 2015.

MMA - Ministério do Meio Ambiente. Sarney Filho destaca importância do selo verde.

Brasília, 2000. Disponível em:

< http://www.mma.gov.br/informma/item/1027-sarney-filho-destaca-importancia-do-seloverde>. Acesso em: 09 set. 2015.

MOURA, A, M, M. O mecanismo de rotulagem ambiental: perspectivas de aplicação no Brasil. IPEA - Instituto de Pesquisa Econômica Aplicada. Boletim regional, urbano e ambiental. $\mathrm{n}^{\circ}$ 7, p. 11, 2013. Disponível em:

<http://ipea.gov.br/agencia/images/stories/PDFs/boletim_regional/131127_boletimregional7_ cap2.pdf $>$. Acesso em: 10 set. 2015.

PINI. ConstruNormas. Instalações hidrossanitárias. Metais sanitários. Torneiras com mecanismos de vedação não compressíveis. 2015. Disponível em:

$<\mathrm{http} / / /$ construnormas.pini.com.br/engenharia-instalacoes/instalacoes-

hidrossanitarias/artigo341253-2.aspx>. Acesso em: 20 set. 2015.

PREUSLLER, M. Rotulagem Ambiental: Um estudo sobre a NBR 14020. XIII SIMPEP

(Simpósio de Engenharia de Produção), Universidade Estadual Paulista "Júlio de Mesquita Filho" - UNESP. Bauru - SP, 2006. Disponível em:

<http://www.simpep.feb.unesp.br/anais/anais_13/artigos/315.pdf>. Acesso em: 09 set. 2015.

PROCEL INFO. Sobre o Procel. O programa, 2015. Disponível em:

<http://www.procelinfo.com.br/main.asp?Team=\%7B505FF883-A273-4C47-A14E-

0055586F97FC\%7D>. Acesso em: 07 jul de 2015a.

PROCEL INFO. Sobre o Procel. Selo Procel, 2015. Disponível em:

<http://www.procelinfo.com.br/main.asp?Team=\%7B505FF883-A273-4C47-A14E-

0055586F97FC\%7D>. Acesso em: 07 jul. 2015 b.

PUB - Singapore's National Water Agency. Water Efficiency Labelling Scheme (WELS), Singapura, 2014. Disponível em: <http://www.pub.gov.sg/wels/Pages/default.aspx>. Acesso em: 26 set. 2015.

RIO+20. Conferência das Nações Unidas sobre Desenvolvimento Sustentável - O futuro que queremos, Rio de Janeiro, 2012. Disponível em: <

http://www.rio20.gov.br/es/documentos/documentos-da-conferencia/esboco-

zero/at_download/esboco-zero.pdf>. Acesso em: 26 set. 2015. 
DEMANBORO, A. C.; MiÑARO, J. P.; LONGO, R. M.; BETTINE, S. C.

Proposta de rótulo ambiental como indicador de eficiência hídrica para torneiras

SCHELL. WELL - Water Efficiency Labeling. The new European label for water and energy-saving sanitary fittings, Alemanha, 2015. Disponível em: < http://www.schell.eu/uploads/tx_dbdownloads/SLL-1743-002_BR_WELL_EN_web.pdf>. Acesso em: 25 set. 2015.

Silva, C. Recursos hídricos e desenvolvimento sustentável no Brasil. Publicação e Documentação, Senado Federal, Brasília, 2012. Disponível em: < http://www12.senado.gov.br/publicacoes/estudos-legislativos/tipos-de-estudos/outraspublicacoes/temas-e-agendas-para-o-desenvolvimento-sustentavel/>. Acesso em: 26 set. 2015.

WATERSENSE. United States Environmental Protection Agency (EPA), Washington - EUA, 2015. Disponível em: < http://www.epa.gov/watersense/>. Acesso em: 16 set. 2015.

WELS - Water Efficiency Labelling and Standards. Austrália, 2015. Disponível em: <http://www.waterrating.gov.au/about-wels>. Acesso em: 20 abr. 2015.

WELL - Water Efficiency Labeling, 2015. Disponível em: <http://www.wellonline.eu/en/default.aspx>. Acesso em: 25 set. 2015.

WSD - Water Supplies Departament. Voluntary Water Efficiency Labelling Scheme on Water Taps, Hong Kong, 2015. Disponível em: <

http://www.wsd.gov.hk/en/plumbing_and_engineering/wels/water_taps/index.html>. Acesso em: 26 set. 2015.

WSD - Water Supplies Departament. Consumer Guidebook, ed. 7, Hong Kong, 2014. Disponível em: <http://www.wsd.gov.hk/filemanager/en/share/pdf/Guidebook-e.pdf>. Acesso em: 26 set. 2015. 
Antonio Carlos Demanboro - Possui Graduação em Graduação em Engenharia Civil. Pontifícia Universidade Católica de Campinas (PUC/Campinas), Mestrado em Engenharia Mecânica pela Universidade Estadual de Campinas (UNICAMP) e Doutorado em Engenharia Civil pela Universidade Estadual de Campinas (UNICAMP). Atualmente é Professor titular da Pontifícia Universidade Católica de Campinas (PUC/Campinas), atuando como pesquisador junto aos Programas de Mestrado em Sistemas de Infraestrutura Urbana, Sustentabilidade e Engenharia Elétrica.

Janaina do Prado Miñarro - Possui Graduação em Engenharia Ambiental e Sanitária pela Pontifícia Universidade Católica de Campinas (PUC/Campinas).

Regina Marcia Longo - Possui Graduação em Graduação em Agronomia pela Universidade Estadual Paulista Júlio de Mesquita Filho (UNESP), Mestrado e Doutorado pela Universidade Estadual de Campinas (UNICAMP). Atualmente é Professora junto aos Programas de Mestrado em Sistemas de Infraestrutura Urbana e Sustentabilidade da Pontifícia Universidade Católica de Campinas (PUC/Campinas).

Sueli do Carmo Bettine - Possui Graduação em Engenharia Civil pela Pontifícia Universidade Católica de Campinas (PUC/Campinas), Mestrado em Engenharia Civil pela Universidade de São Paulo (USP) e Doutorado em Engenharia Civil pela Universidade Estadual de Campinas (UNICAMP). Atualmente é Professora junto aos Programas de Mestrado em Sistemas de Infraestrutura Urbana e Sustentabilidade da Pontifícia Universidade Católica de Campinas (PUC/Campinas).

Artigo recebido em: 30 de outubro de 2017.

Artigo aceito em: 18 de abril de 2018.

Artigo publicado em: 30 de junho de 2018. 